\title{
Understanding the Usage of Social Networks Apps Among Organizations and Its Impact on Team Performance: Empirical Study
}

\author{
Nasser A. Saif Almuraqab ${ }^{1}$ \\ ${ }^{1}$ Dubai Business School, University of Dubai, Dubai, United Arab Emirates \\ Correspondence: Nasser A. Saif Almuraqab, Dubai Business School, University of Dubai, Dubai, United Arab \\ Emirates.
}

Received: June 28, 2019

Accepted: July 19, 2019

Online Published: July 23, 2019

doi:10.5430/jms.v10n4p7

URL: https://doi.org/10.5430/jms.v10n4p7

\begin{abstract}
Nowadays in the digital era the development of applications influences the process of group collaboration. And social networks apps usage among enterprises and institutions is growing enormously. Most of the researches on social networks technologies usage are focused on the individual viewpoint, while others are from the organizational viewpoint. Nevertheless, not many research works have examined the actual influence of social networks apps usage via smart devices on team's performance. The need of communication in group teamwork while doing tasks or projects, forces the team to plan their meetings to finish tasks given. Therefore, using the quantitative approach, this research aims to reveal the predictors that drive the employees to use social networks technologies, and the consequences of using these technologies in team performance. This research model was validated using Partial Least Squares approach with on 110 respondents. The results disclosed that perceived ease of use, perceived compatibility, perceived usefulness, and perceived interactivity of the social network applications, drive the employees to use these applications when performing their group projects. In addition, collaborative working is also a significant predictor for the employees to use social networks applications. Also, the use of social networks technologies also showed a positive impact on team performance.
\end{abstract}

Keywords: social networks usage, team performance, technology acceptance, collaborative working, interactivity

\section{Introduction}

The usage of social networks applications within enterprises is changing communication. Social networks applications enable open communications, which motivate them to work and collaborate more efficiently (Praveen et al., 2016). Working on tasks in a team or group requires the ability to adjust and manage time, so the members can exchange information which will lead them to resolve the problem in any task or project. Processes such as communication and coordination, besides other factors for i.e. trust, understanding, conflicts, and consistency will yield to concerns in the collaboration among group members due to different time and place (Naik and Kim, 2010). With the presence of advanced ICT, team members will not bother about how adjusting physical meeting schedule. They can conduct conversations at any time, even from different locations (Munkvold, 2003). Social networks apps as a type of collaborative technologies, support group's activities by providing coordination and ease of interaction among the members. Outcomes of previous research works showed many advantages from the use of collaborative technologies. The use of these apps also showed to enhance the quality of communication among groups' members. This resulted by the interaction among users is becoming more noticeable, which will improve understanding (Ma, 2009). Furthermore, the use such collaborative technologies also boost collaborating process, where members can develop new information socially (Kreijns and Kirschner, 2002).

Though previous scholars stated the advantages and familiarity of social networks technologies, there were few studies regarding adoption factors of these applications and its impact to team performance.

This study was conducted at the United Arab Emirates (UAE) among employees from different companies and sectors, emails list generated from University of Dubai. Considering their usage of social networks applications, to assist their different groups/team activities. Additionally, they represent different type of organizations and sectors in UAE (government and private) so that the author considered them as suitable respondents for this study. For the aim of this paper, the terms social networks apps/applications/technologies and also group/team are used interchangeably. 


\section{Literature Review}

Social network technologies are a platform that simplifies information exchanging among users of these technologies to generate and/or spread the content (Steenkamp and Hyde-Clarke, 2014). These technologies have moved the importance of internet to becoming more collaborative and interactive, thus creating new prospects for communication between institutions and the community (Henderson and Bowley, 2010). Away from old methods of social media, social networks technologies have both mobile applications and web-based portals

Mou et al., 2013, the sophisticated level of competence of social networks apps equated to other outdated communication media prompted business decision makers to state that enterprises should participate in i.e., Twitter, Facebook, Instagram, WhatsApp, and others, to prosper in digital era (Kaplan and Haenlein, 2010).

The increasing trend of social networks technologies has also encouraged many scholars to do study this arena. However, utmost of the research on social networks tools have covered the individual perspective (Coyle and Vaughn, 2008; Gangadharbhatla, 2008; Agarwal and Mital, 2009; DeKay, 2009; Pelling and White, 2009). In addition, research on organizational acceptance of social networks apps are fairly limited, and specially its extent to team performance, in the digital era, where employees rely on their smart devices using these (social networks) applications to communicate and collaborate, which is considered as an academic challenge by the author.

Therefore, some of the research that investigated social networks apps usage amongst organizations is deliberated below, to highlight the literature gap which this paper is tempting to fill.

Scholars for instance Curtis et al. (2010), utilizing the (UTAUT) Unified Theory of Acceptance and Use of Technology, recognized the usage of social media tools by non-profit institutions. The consequences of this study showed that these tools are becoming advantageous means of communication in the non-profit segment especially by public relations department. PR departments are more probable to accept social network tools and utilize them to reach their objectives.

Sparrowe et al., (2001) did an empirical research work involving 38 working groups from different organizations to reveal the impact of social networks apps and the performance on individuals and groups, they reported that individual job performance was positively related to centrality in advice networks and negatively related to centrality in hindrance networks composed of relationships tending to thwart task behaviors. Furthermore, their study reported that hindrance network density was significantly and negatively related to group performance.

In addition, Koo et al. (2011) applied the social theories and media richness theory studied how social communication tools can be utilized by an employee to fit her/his task characteristics. Moreover, it also investigated how the employee's social relations moderated media practice in the current job situation and how this usage affected her/his performance. The findings showed that task features were related to social media usage, whereas social aspects moderated the level of the associations. Furthermore, the usage of social media technologies outcomes performance in doing tasks.

Also, Praveen et al (2014) did a study on social media tools and its reflection on the organizational performance, and specifically on the social media managers, the study revealed that social media has a greater impact on the performance of organizations in terms of enhancement in customer relations and customer service activities, improvement in information accessibility and cost reduction in terms of marketing and customer service. Similarly, Hidayanto and Setyady (2014) did a study on the effect of social networks technologies and other collaborative tools on group performance, they reported that perceived usefulness, perceived ease of use of collaborative technologies effect the groups (students) to use these technologies when working at their group's assignments. Also, it was reported that usage of collaborative technologies positively affects the group performance.

Finally, a current study by Tajudeen et al., (2018) explored the factors and impact of social media tools usage in institutions, their research utilized Technology-Organization-Environment (TOE) framework combined with other factors related to social networks technologies use in institutions. It reported the impact of social media adoption by organizations and its benefits on the performance.

As can be understood from the literature, most of them studied the overall use of social networks technologies or collaborative tools i.e. (Video-conference, Skype, E-mail, etc.) for businesses, with very limited having examined the impact of latest social networks apps via smart devices on team performance, i.e. (WhatsApp, Facebook, Telegram, LinkedIn), which is an academic challenge and will enrich the literature by examining the latest social network technologies and its impact on performance of the team in organizations.

In fact, and as per Torkzadeh and Doll (1999), the influence of IT/IS can be observed from the attitude-behavior or 
technology acceptance theory. Considering this, the study aimed to response study questions:

1- What are the predictors affect employees to adopt social networks apps for their team tasks?

2- Dose the usage of social networks apps influence team performance?

3- Shall the senior management encourage employees to use social networks apps for better team performance?

\subsection{Research Model and Hypotheses}

Technical predictors are the perceived features of the technology to be accepted (DePietro et al., 1990). Based on the TAM theory, as suggested by Davis (1989), TAM model describes technology features which influence users' intention to accept and use a technology. The utilization of social network tools is anticipated to provide numerous advantages to organizations, for instance ease of exchanging ideas via social network apps using smart devices (smartphones) more convenient and faster than desktop applications for instance email. Social networks are anticipated to help team members to exchange ideas, communicate related to the group's responsibilities to be accomplished, and to handle documents produced from the group projects so that development can be observed by all team members. Therefore, it drives to first two hypotheses as follow:

H1: Perceived ease of use (PE) will positively influence employees' intention to use (ITU) Social networks apps.

H2: Perceived usefulness (PU) will positively influence employees' intention to use (ITU) Social networks apps.

Correspondingly, compatibility is also a technological aspect recommended by DOI as a factor on decision to accept a new technology (Rogers, 1983). Once a tool is constant with the existing culture, values, ICT, and favored work does of the organization, then it is more possible to be used. Numerous previous research works reported that more compatible tools is more probable to be accepted (Hong and Zhu, 2006; Wang et al., 2010; El-Gohary, 2012; Almuraqab, 2016; Tajudeen et al., 2018)

H3: Perceived compatibility (PC) will positively influence employees' actual use (AU) of social networks apps.

According to TAM intention to use social networks should be associated with the actual use. TAM by (Davis, 1989) argued that actual use of these apps is predicted by perceived ease of use, perceived usefulness and users' intention to use the IT. On this study, researcher expects that employees with intention to use social networks in doting their tasks will drive to actual use of social networks applications as a channel to finish the group work. So, it presents fourth hypothesis as follows:

H4: Intention to use (ITU) will positively influence employees' actual use (AU) of social networks apps.

Interactive digital tools are more probable and speedily accepted by users (Rogers 1995). Social networks are considered as a collaborative tool. It empowers two-way interaction rather than one-way outdated directional distributions or transmissions of info (Mayfield, 2008). Social networks platforms, including LinkedIn, Facebook, Instagram, and WhatsApp have become universal; organizations have rushed to adopt and configure social networks into their websites, empowering collaborative communications among consumers, and/or between consumers and firms (Lee and Kozar, 2009) or between employees themselves. The interactivity factor has not been considered seriously by scholars (Tajudeen et al., 2018). Though, seeing the interactive feature of social networks technologies, this study embraces the interactivity variable and examines its influence on the use of social networks in team performance, among employees. Consequently, the hypothesis is defined as follows:

H5: Perceived interactivity (PI) will positively influence employees' actual use (AU) of social networks apps

Team members have activities for i.e. discussion and collaboration, among members drive to practice their communication skills and to think critically (Kreijns et al., 2003). In addition, the importance of joint working doings for employees triggers the need exchange of information among team's members. In fact, this could be a problem because of many issues such as the time required to exchange thoughts, information complication, and the quality of the media. However, the advanced networks and information technology are solution to enhance collaboration activities to be more efficient and effective (Line, 1997). Furthermore, Munkvold (2003) argued that collaborative working activities positively impact its users to use the collaborative tools. Bratteteig (1998) also argued that collaborative working activities must be there pre-adopting the technology. Hidayanto and Setyad, (2014) found that collaborative working has positive impact on collaborative tools adoption. Thus, research stated the sixth hypothesis:

H6: Collaborative working activities (CW) will positively influence employees' actual use (AU) of social networks apps.

Becker and Cline, (2005) defined group's effectiveness of planning and managing meetings' timing, the presence of information exchange between each other, and to monitor and evaluate performance. Many options offered by social 
networks can sustenance and streamline the process of groups to do collaboration, so it is anticipated that the use of social networks will improve team's performance. Previous studies in this field for i.e. Majumdar and Krishna (2012) discussed the impact of advance web 2.0 technology capabilities on group's interaction. Correspondingly, a study revealed how use of collaborative tools positively affects the performance of workgroup's collaboration Elie-Dit-Cosaque and Pallud (2012). In addition, Hidayanto and Setyad, (2014) discussed that collaborative tools positively impact on workgroup's performance. Thus, it is expected that the use of social networks via smart devices will positively impact team performance, which drives to the last hypothesis:

H7: The actual use (AU) of social networks apps will positively influence employees' team's performance (TP).

The proposed research model is shown in Figure 1 below.

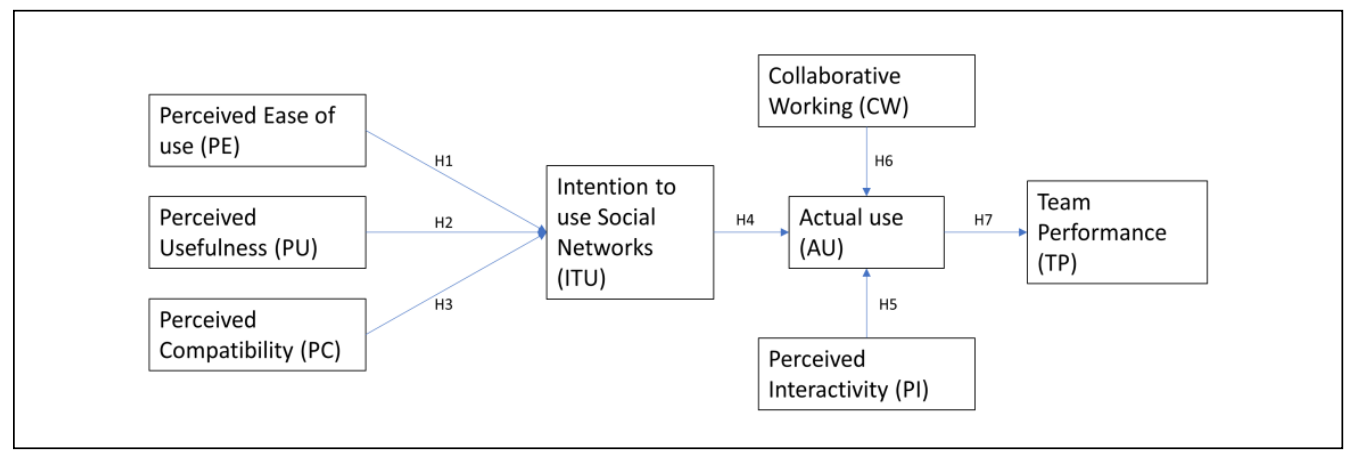

Figure 1. Proposed model and hypotheses

The proposed model is a combination of Technology Acceptance Model (TAM) main PE and PU constructs with other variables like compatibility and collaborative working, and interactivity, in agreement with the model that say team activities will require the use of social networks to enhance communication and exchange of information among team members (Line, 1997). The framework also represents the association of the use of social networks and its impact team performance.

\section{Method}

This study utilizes quantitative research methodology (Creswell, 1994) to prove the proposed hypotheses. To examine our model, an empirical work was considered using a survey tool that measure the constructs anticipated to the acceptance of social networks. The questionnaire items were obtained from theories and previous research. Constructs and items have been used in this study are explained in the Table 1 below:

Table 1. Constructs and items of the questionnaire

\begin{tabular}{|c|c|c|}
\hline Variable/Construct & Indicator/Items & References \\
\hline \multirow{4}{*}{$\begin{array}{l}\text { Perceived Ease of use } \\
\text { (PE) }\end{array}$} & Learn how to function social networks is easy to me & \multirow{4}{*}{$\begin{array}{l}\text { (Davis, 1989; Moore and } \\
\text { Benbasat, 1996; Taylor and } \\
\text { Todd, 1995; Venkatesh and } \\
\text { Davis, 2000; Almuraqab, 2016) }\end{array}$} \\
\hline & $\begin{array}{l}\text { I can use social networks' features to get the results I } \\
\text { want }\end{array}$ & \\
\hline & I can remember how to operate social networks & \\
\hline & In general, I can run the social networks easily & \\
\hline \multirow[t]{3}{*}{$\begin{array}{l}\text { Perceived Usefulness } \\
\text { (PU) }\end{array}$} & $\begin{array}{l}\text { Use of social networks enhances my efficiency in } \\
\text { group's tasks }\end{array}$ & \multirow{3}{*}{$\begin{array}{l}\text { (Davis, 1989; Moore and } \\
\text { Benbasat, 1996; Taylor and } \\
\text { Todd, 1995; Venkatesh and } \\
\text { Davis, 2000; Almuraqab, 2016) }\end{array}$} \\
\hline & $\begin{array}{l}\text { Use of social networks makes the collaborative } \\
\text { working easier }\end{array}$ & \\
\hline & $\begin{array}{l}\text { Social networks make the cooperative working } \\
\text { process more operative. }\end{array}$ & \\
\hline
\end{tabular}


Use of social networks increases team performance.

\begin{tabular}{ll}
\hline $\begin{array}{l}\text { Intention } \text { (ITU) } \\
\text { to Use }\end{array}$ & $\begin{array}{l}\text { I intend to use social network applications at group's } \\
\text { works }\end{array}$ \\
& $\begin{array}{l}\text { I will use social networks applications at group's tasks } \\
\text { in future }\end{array}$ \\
& $\begin{array}{l}\text { I plan to use social network applications at group's } \\
\text { projects frequently }\end{array}$ \\
\hline Actual Use (AU) & $\begin{array}{l}\text { I use social networks to debate and share ideas and } \\
\text { information with team members, to complete group's } \\
\text { task. }\end{array}$ \\
& $\begin{array}{l}\text { I use social networks to monitor the progress of } \\
\text { group's tasks. }\end{array}$ \\
& $\begin{array}{l}\text { Overall, I use social networks to complete group's } \\
\text { tasks. }\end{array}$ \\
& $\begin{array}{l}\text { I collaborate with colleagues to finish group tasks. } \\
\text { Collaborative } \\
\text { Working (CW) }\end{array}$ \\
& $\begin{array}{l}\text { I share material and when cooperating with my team } \\
\text { members. }\end{array}$ \\
& $\begin{array}{l}\text { Collaborative actions involve task circulation among } \\
\text { group/team members. }\end{array}$ \\
\hline Team & $\begin{array}{l}\text { Social networks use facilitates the task schedule } \\
\text { planning to become more convenient. }\end{array}$ \\
& Performance
\end{tabular}

(Davis, 1989; Moore and

Benbasat, 1996; Taylor and

Todd, 1995; Venkatesh and

Davis, 2000; Almuraqab, 2016)

I plan to use social network applications at group's

frequently

(Beal and Rogers, 1960; Davis,

1989; Bajwa and Lewis, 2003;

Kittle and Hicks, 2009;

Lanubile et al., 2010)

(Beal and Rogers, 1960; Davis, 1989; Kittle and Hicks, 2009)

(Beal and Rogers, 1960; Davis, 1989).

(Patel, Pettitt, and Wilson,

2012; Hidayanto and Setyad, 2014)

(Singh and Avital, 2007;

Hidayanto and Setyad, 2014)

(Becker and Cline, 2005; Gress et al., 2010; Serce et al., 2011;

Majumdar and Krishna, 2012

Hidayanto and Setyad, 2014)

Social networks utilization makes the monitoring of Becker and Cline, 2005; Gress task's progress activities easier. et al., 2010; Majumdar and Krishna, 2012; Hidayanto and Setyad, 2014)

The using of social networks makes the procedure of (Bajwa and Lewis, 2003; task compiling and task arrangement easier.15-24 Nikas, Poulymenakou, and Kriaris, 2007; Kittle and Hicks, 2009; Hidayanto and Setyad, 2014)

Social networks utilization become the media to share information within group/team.

(Hoegl and Gemuenden, 2001; Becker and Cline, 2005; Gress et al., 2010; Hidayanto and Setyad, 2014)

Overall, social networks utilization facilitates me to (Hoegl and Gemuenden, 2001; contribute in completing group's tasks. Lanubile et al., 2010; Hidayanto and Setyad, 2014)

Other team members and I help each other when using (Hoegl and Gemuenden, 2001; social networks. Hidayanto and Setyad, 2014)

Social networks become (Hoegl and Gemuenden, 2001; interaction channel to provide feedback of task's results among group/team members.

Serce et al., 2011; Hidayanto and Setyad, 2014)

\begin{tabular}{lllll}
\hline Perceived & Using social networks fits with the way I work in (Rogers, 1995; Almuraqab,
\end{tabular}




\begin{tabular}{|c|c|c|}
\hline \multirow[t]{3}{*}{ compatibility (PC) } & group/team & \multirow[t]{3}{*}{ 2016) } \\
\hline & $\begin{array}{l}\text { Using social networks fits with my practice } \\
\text { preferences }\end{array}$ & \\
\hline & Using social media fits with group/team transactions & \\
\hline \multirow[t]{4}{*}{$\begin{array}{l}\text { Perceived } \\
\text { Interactivity (PI) }\end{array}$} & $\begin{array}{l}\text { Collaborative features of the social networks apps that } \\
\text { we use (e.g., WhatsApp, Telegram) are enhancing } \\
\text { responses. }\end{array}$ & \multirow[t]{4}{*}{$\begin{array}{l}\text { (Lee and Kozar, 2009; } \\
\text { Tajudeen et al., 2018) }\end{array}$} \\
\hline & $\begin{array}{l}\text { Social networks apps provide features for } \\
\text { collaborative communication among group/team } \\
\text { members }\end{array}$ & \\
\hline & $\begin{array}{l}\text { The social networks apps provide a suitable number } \\
\text { of collaborative aspects (e.g., documents, photos, } \\
\text { music, voices). }\end{array}$ & \\
\hline & $\begin{array}{l}\text { The social networks apps contain mechanisms to help } \\
\text { the communication among group/team members. }\end{array}$ & \\
\hline
\end{tabular}

\subsection{Population, Samples and Data Collection Procedures}

The electronic questionnaire was developed as the following: first the researcher used a pilot with a limited number of participants to examine the dependability of the model. This process was followed by testing the data using SmartPLS using Cronbach's alpha reliability, coefficient, which ensures the consistency of the survey items. Regarding the sample size, the researcher planned to distribute the survey electronically aiming to collect at least 70 participants if applicable, to fulfill the condition of analysis using SmartPLS which is mandatory that the sample should minimum ten times the largest of formative items used to measure a construct or ten times the largest number of structural paths directed at dependent construct. So, the largest number is seven.

After that, the researcher used electronic mail lists of the University of Dubai, to share the questionnaire link for participation. The data collection started from $9^{\text {th }}$ of Dec 2018 and continued till $14^{\text {th }}$ of Jan 2019 , collecting of a total 152 participants. A primary regression analysis was done to remove the outliers that surpassed limits of specific measure or were extremely odd, as well as un-completed responds. So, the sample size utilized for the examination is 110, which contents the terms and the suitability of analysis. The sample demographics are shown in Table 2.

Table 2. The demographic of the sample

\begin{tabular}{lll}
\hline Gender & Frequency & Percentage \\
\hline Male & 70 & $64 \%$ \\
\hline Female & 40 & $36 \%$ \\
\hline Education level & \\
\hline High school or less & 10 & $9 \%$ \\
\hline Diploma & 3 & $3 \%$ \\
\hline Bachelor & 54 & $49 \%$ \\
\hline Master & 38 & $35 \%$ \\
\hline PhD Or Doctoral degree & 5 & $5 \%$ \\
\hline Age & & \\
\hline $18-24$ & 5 & $5 \%$ \\
\hline $25-34$ & 41 & $37 \%$ \\
\hline $35-44$ & 50 & $45 \%$ \\
\hline
\end{tabular}




\begin{tabular}{lll}
\hline $55-64$ & 13 & $12 \%$ \\
\hline 65 or more & 1 & $1 \%$ \\
\hline Social networks & & \\
\hline WhatsApp & 92 & $84 \%$ \\
\hline LinkedIn & 3 & $3 \%$ \\
\hline Facebook & 2 & $2 \%$ \\
\hline Google Hangouts & 2 & $2 \%$ \\
\hline Skype & 1 & $1 \%$ \\
\hline Telegram & 1 & $1 \%$ \\
\hline Other & 9 & $8 \%$ \\
\hline
\end{tabular}

\subsection{Instruments}

This research applied a survey containing of three parts, the first presented the study and its objectives as well as the researcher. Such introduction was central as respondents were from UAE. The second part was modest demographic questions for i.e. gender, age, and education. The last part included 31 items measuring eight variables drawn from earlier relevant studies. Such adoption supports the rationality of the instrument and enhances the dependability. This study extended the technology acceptance model theory by adding several variables such as compatibility, collaborative working, interactivity, and team performance, to answer the research questions. The items' distributions are shown in Table 3, which contains estimate of items' average, and standard deviations. This procedure is important for the content strength and tool's reliability.

Table 3. The items' distributions

\begin{tabular}{|c|c|c|c|c|c|c|c|c|c|c|}
\hline & Mean & Standard Deviation & Meas & remen & tems 1 & dings & & & & \\
\hline & & & $\mathrm{PE}$ & PU & $\mathrm{PC}$ & PI & $\mathrm{CW}$ & ITU & $\mathrm{AU}$ & TP \\
\hline PE1 & 4.23 & 0.63 & 0.62 & & & & & & & \\
\hline PE2 & 3.97 & 0.74 & 0.72 & & & & & & & \\
\hline PE3 & 3.90 & 0.81 & 0.83 & & & & & & & \\
\hline PE4 & 4.23 & 0.64 & 0.74 & & & & & & & \\
\hline PU1 & 3.93 & 0.75 & & 0.84 & & & & & & \\
\hline PU2 & 4.07 & 0.71 & & 0.86 & & & & & & \\
\hline PU3 & 3.99 & 0.75 & & 0.87 & & & & & & \\
\hline PU4 & 3.80 & 0.78 & & 0.87 & & & & & & \\
\hline PC1 & 3.79 & 0.73 & & & 0.89 & & & & & \\
\hline PC2 & 3.78 & 0.79 & & & 0.89 & & & & & \\
\hline PC3 & 3.83 & 0.80 & & & 0.87 & & & & & \\
\hline PI1 & 3.97 & 0.74 & & & & 0.82 & & & & \\
\hline PI2 & 3.99 & 0.69 & & & & 0.87 & & & & \\
\hline PI3 & 4.26 & 0.64 & & & & 0.79 & & & & \\
\hline PI4 & 4.08 & 0.62 & & & & 0.84 & & & & \\
\hline CW1 & 3.98 & 0.66 & & & & & 0.87 & & & \\
\hline CW2 & 4.06 & 0.70 & & & & & 0.86 & & & \\
\hline
\end{tabular}




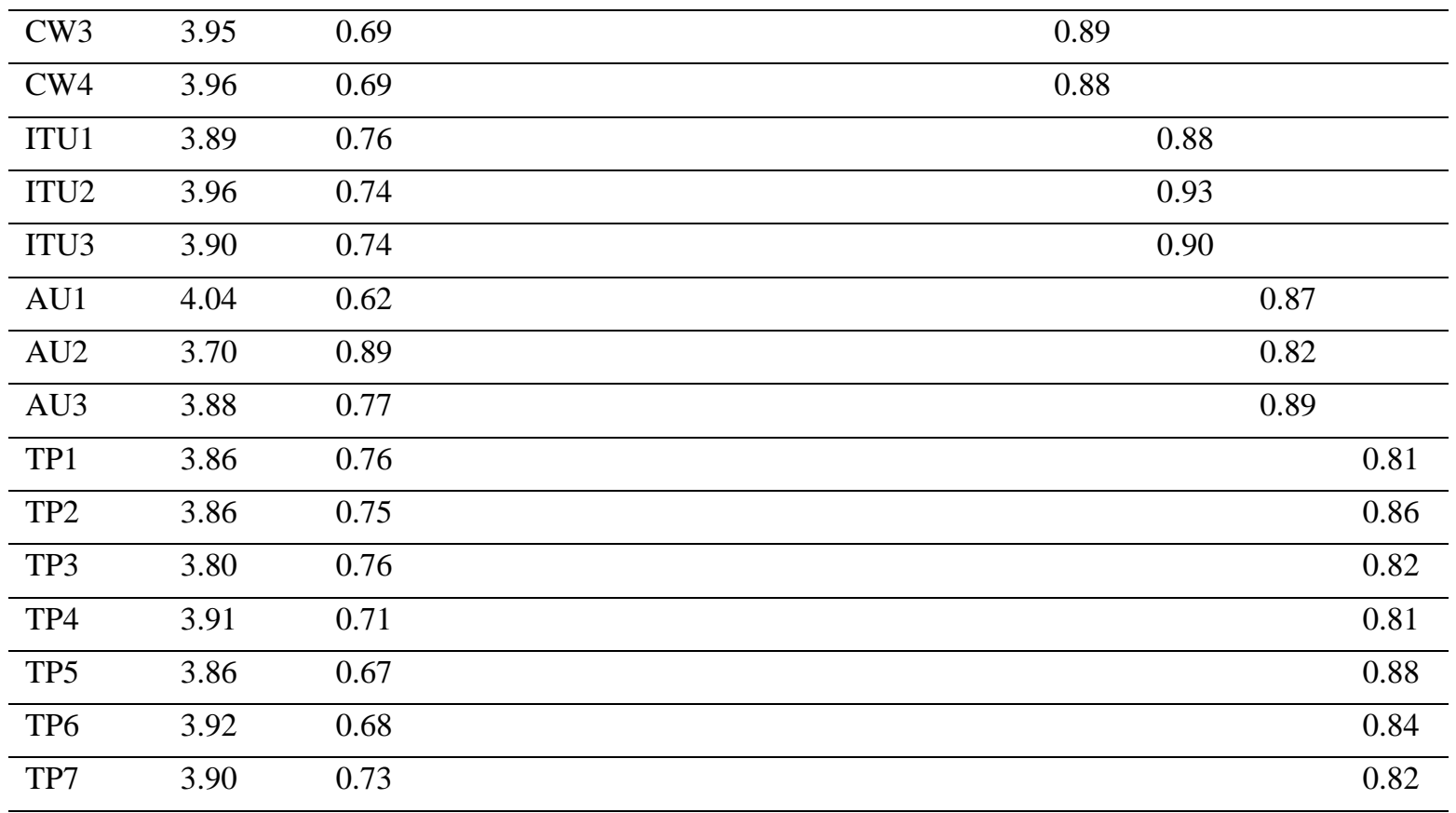

\begin{tabular}{lllllllll}
\hline Cronbach's Alpha & 0.75 & 0.88 & 0.86 & 0.85 & 0.90 & 0.89 & 0.82 & 0.93 \\
\hline Composite Reliability & 0.83 & 0.92 & 0.91 & 0.90 & 0.93 & 0.93 & 0.89 & 0.94 \\
\hline Average Variance Extracted (AVE) & 0.55 & 0.74 & 0.78 & 0.68 & 0.77 & 0.82 & 0.74 & 0.70 \\
\hline
\end{tabular}

\section{Results}

An analysis was conducted, using an application licensed by University of Dubai called SmartPLS (Ringle et al., 2005). Structural Equation Modelling (SEM) evaluates the measurement and structural models concurrently, therefore doing factor analysis and hypothesis checking simultaneously (Gefen, Straub, and Boudreau, 2000). Partial Least Square (PLS) was used rather than covariance-based SEM since it is suitable for exploratory type of research (Gefen et al., 2000).

In addition, to guarantee that items/questions used on this paper were perceived highly, a communal method in social disciplines when utilizing a Likert scale 1-5 reflects (1-2.33) as low, (2.33-3.67) as average and (3.67-5) as high. Table 3 above represents the means, standard deviations and measurement loadings of all items used for all eight constructs.

After that, the researcher measured both convergent and discriminant validities. The validity of the convergent was proved after examining Cronbash's Alpha, Composite Reliability, Average Variance Extracted (AVE) and item loadings. Which all surpassed the suggested threshold values (0.70) for composite reliabilities (Fornell and Larcker, 1981), 0.70 for Cronbach's alpha, 50\% for Average Variance Extracted (AVE), and 0.60 for items loadings, Field (2005) supports the suggestion of Guadagnoli and Velicer (1988) to regard a factor as reliable if it has four or more loadings of at least 0.6 irrespective of sample size.

It is necessary to check the correlations matrix, before answering the research question. To establish construct discriminant validity, Fornell and Larcker (1981) stated that the square root of AVE must be higher for every variable than its correlation with other variables. The inter-variable correlation matrix is illustrated in Table 4 with square root of AVE presented in bold. 
Table 4. Discriminant validity

\begin{tabular}{lllllllll}
\hline & AU & CW & ITU & PC & PEOU & PI & PU & TP \\
\hline AU & $\mathbf{0 . 8 6}$ & & & & & & & \\
\hline CW & 0.62 & $\mathbf{0 . 8 8}$ & & & & & & \\
\hline IU & 0.65 & 0.66 & $\mathbf{0 . 9 0}$ & & & & & \\
\hline PC & 0.54 & 0.60 & 0.59 & $\mathbf{0 . 8 8}$ & & & & \\
\hline PE & 0.41 & 0.54 & 0.51 & 0.54 & $\mathbf{0 . 7 3}$ & & & \\
\hline PI & 0.56 & 0.71 & 0.56 & 0.62 & 0.51 & $\mathbf{0 . 8 3}$ & & \\
\hline PU & 0.56 & 0.69 & 0.62 & 0.70 & 0.56 & 0.70 & $\mathbf{0 . 8 6}$ & \\
\hline TP & 0.75 & 0.76 & 0.67 & 0.61 & 0.51 & 0.73 & 0.71 & $\mathbf{0 . 8 4}$ \\
\hline
\end{tabular}

Adding to the above displayed results, and to answer the study questions, an SEM examination using SmartPLS application and algorithms was directed. A PLS-SEM doesn't assume normality but depend on a non-parametric Bootstrap technique to examine the model, which means man lesser subsamples are inherited from the research sample and verified to get the best fit of the model. SmartPLS application proposes and estimates simply the item loadings and the correlations, the results are shown in Table 4.

SmartPLS calculates both $T$ and $P$ values for every test to demonstrate significance of outcomes for both path coefficients as shown in Table 5.

A bootstrapping method is used to reveal $t$ and $p$ values. The researcher considered 0.1 since the scope of study is related to management and social science, and it is not relating to monetary loss.

The tested model significantly explains TP with an $\mathrm{R}^{2}$ value equal to (0.56). Also, the beta values and their " $t$ " values and " $p$ " values are reflected in Table 5 below.

Table 5. T-values and P-values with hypothesis status $* \mathrm{p} \leq 0.1 \quad * * \mathrm{p} \leq .05 \quad * * * \mathrm{p} \leq .01$

\begin{tabular}{lcllll}
\hline Hypotheses & & Path coefficient & $T$ Value & $P$ Value & Hypothesis status \\
\hline $\mathrm{H} 1 \mathrm{PE} \longrightarrow$ & ITU & 0.18 & 1.85 & $0.06^{*}$ & Supported \\
\hline $\mathrm{H} 2 \mathrm{PU} \longrightarrow$ & ITU & 0.35 & 3.87 & $0.00^{* * *}$ & Supported \\
\hline $\mathrm{H} 3: \mathrm{PC} \longrightarrow$ & $\longrightarrow$ & 2.35 & $0.01^{* * *}$ & Supported \\
\hline $\mathrm{H} 4: \mathrm{ITU} \longrightarrow$ & 0.25 & 4.14 & $0.00^{* * *}$ & Supported \\
\hline $\mathrm{H} 5: \mathrm{PI} \longrightarrow$ & AU & 0.41 & 1.70 & $0.08^{*}$ & Supported \\
\hline $\mathrm{H} 6: \mathrm{CW} \longrightarrow$ & AU & 0.17 & 2.03 & $0.04^{* *}$ & Supported \\
\hline $\mathrm{H} 7: \mathrm{AU} \longrightarrow$ & AU & 0.24 & 13.66 & $0.00^{* * *}$ & Supported \\
\hline
\end{tabular}

\subsection{Hypotheses Analysis}

The relations test between constructs in the proposed model based on $t$-value and p-value showed in Table 5. In fact, all the proposed hypotheses in this research are accepted.

The first hypothesis is accepted. This means if employees can operate social networks apps easily to do group's projects working as a team, it will drive the intention to use social networks application.

Second hypothesis is accepted. This result shows that when employees believe that social networks apps are useful towards improving their group/team performance, there will be an intention to use social networks technologies.

Third hypothesis is also accepted. This means that if employees feel social networks apps are compatible with their work and lifestyle especially when doing group's project, it will encourage their intention to use social networks applications.

Fourth hypothesis is accepted. That means employees' intention to use social network apps proved to predict the 
actual use of social networks applications as helpful technologies to accomplish group's project. It indicates that the more employees have intention to use social network applications to do group work, will drive to actual use these apps.

Fifth hypothesis reflects that perceived interactivity of social networks apps positively influences employees' actual use of social networks applications to do their group's project. This indicates that when employees are assigned to work as a team on a group project, which involve interactivity among the members, they will use social networks technologies that support the interaction process in their group tasks.

Whereas the sixth hypothesis represents that the cooperative working activities significantly has a positive impact on the actual use of social networks applications to finish group project. This suggest when employees are assigned a group's work which encompass cooperative working, they will utilize social networks apps that enhance exchange of information and communication process in their responsibilities.

The last seventh hypothesis (H7) also reflects a significant association between the actual use of social network apps and team performance in doing their team projects. This indicates when employees use social networks applications to complete their project, then team performance will improve.

\section{Discussion}

This study conducted to reveal the predictors that will influence employees' adoption of social networks applications, towards better team performance. This paper tempts to fill a gap highlighted on the literature previously explained.

Research findings reflect that TAM by Davis (1989), is able clarify the use of social networks technologies in this study, and it can be extended with other variables to explain the impact of these technologies on team performance. Further explanation of the research results is clarified below.

Data analysis results showed that perceived usefulness and perceived ease of use of social networks technologies positively influence employees' intention to use social networks applications in doing team tasks.

Perceived usefulness of social networks apps represented by the increased team efficiency, increased effectiveness and simplify members collaboration, which improves team performance. Employees' intention to use social networks apps indicated by willingness to use these tools in working as a team and do group's works, and willingness to utilize social networks applications. In addition, this infers that employees will intent to use the social networks apps more, if it can be operated easily and it is useful for them for their group projects.

Correspondingly, the compatibility of social networks apps was found to be significant determinant that is positively correlated with intention to use social networks technologies in firms $(\mathrm{P} \leq 0.01)$. Employees have internet connection most of the time, on their smart devices and they use these tools, because they are highly compatible with the employees' work style and especially in doing group's task, as the technology is very convenient, simple, and effective. The outcome of compatibility test was reliable with previous research, which reported that compatibility is an important predictor in the acceptance of information systems and technologies (El-Gohary, 2012; Wang et al., 2010; Almuraqab, 2016).

In addition, results analysis presented positive association between employees' intention to use social networks apps and actual use. Actual use of these applications explained by the consumption of social networks apps to share and discuss ideas or opinions among team's members when having group tasks, and to monitor project progress. Thus, intention to use must be before the employees' actual use of the social networks technologies.

The interactivity factor is also a critical predictor that controls the use of social networks in firms $(\mathrm{P} \leq 0.1)$. The collaborative nature of social networks apps allows two-way communication among group members, to perform better in practicing group project, which motivates them to use these applications. Collaborative inventions provide two-way communication and enhance the acceptance process because they fascinate users speedily (Lee and Cho, 2011; Al-Qirim, 2007). This finding was constant with previous research, which recommended that interactivity of any application has a solid impact on technology acceptance (Pituch and Lee, 2006; Lee and Kozar 2009; Tajudeen et al., 2018).

Hypotheses testing showed that collaborative working positively affect actual use of social networks apps while doing group project when working as a team. Collaborative working is employees' collaboration to complete a project, also the exchange of information among team members.

Also, group collaboration is effective when members distribute the tasks similarly and then debate each progress together. Collaborative activities need facilities to improve information sharing and knowledge exchange and sharing references. Regardless of the location and time of every member. Because team project is required and has target, 
employees will use social networks technologies to finish their tasks on time from any place, rather than meeting physically. Numerous features provided by social networks applications can help employees to collaborate better, chat, exchange files, modify and edit documents concurrently, and it is more convenient especially with the use of smart devices.

Finally, the analysis presented a positive association among actual use of social networks apps and team performance. In this regard, team performance was measured by some factors, such as project planning, monitoring the progress, easily conducting and joining coordination process, and the information exchanging. Other indicators such as every member can deliver contribution to his/her group, supports each other, and communicate every task's feedback among the group members. In addition, the proved positive relationship between actual use of social networks and team's performance indicated that if employees use social networks in doing their group projects, then their team performance will advance. Such finding is similar to the studies of (Majumdar and Krishna, 2012; Elie-Dit-Cosaque and Pallud, 2012; Hidayanto and Setyady, 2014), on the field of collaborative technologies utilization and the team's performance.

\subsection{Practical Contribution}

Study results reported; the usage of social networks apps positively influence on team performance. Thus, employees are anticipated to use these technologies in their team projects or tasks, because it is confirmed to advance the process of collaboration including communication, interaction, as well as exchanging of info between associates. In addition, employees can make use of these applications that have been enhanced with many features supporting group collaboration for group work activities. Furthermore, organizations and senior management may want to pay greater attention to helping employees or group/team leaders build the culture of using social networks applications to enhance group performance, specially the apps with group features i.e. (WhatsApp, LinkedIn, Google-hangout), this will improve the teams' performance because certainly employees will not be able to physically meet at all the times. Collaborative working is a great choice for senior managers to boost employees' usage of social networks applications as it showed to be one of factors of the use of these technologies. The usage of social networks apps may support the team to work better, more effective, efficient, and facilitate the decision making as well as information sharing, regardless of place and time.

Finally, the findings of this research also presented that the perceived usefulness, compatibility, perceived ease of use, and perceived interactivity predict the use of social networks applications for the working groups. Correspondingly, developers of social networks applications are expected to frequently evaluate their solutions to always be useful, compatible work preferences, as well as easy to use, plus to keep consideration the interactivity features. While features in existing social networks technologies now support the teamwork, there are prospects to add more innovative features that deliver more benefits of employees who are using it for group projects/tasks.

\subsection{Theoretical Contribution}

As explained earlier, researches based on organizational acceptance of social networks apps are quite limited, and specially its extent on team performance. Considering the context of social networks technologies, there is an absence of research that investigate team performance of these apps in an integrated model (Devaraj and Kohli, 2003; Tajudeen et al., 2018). Consequently, the current paper, which uses a combined model, examines the factors of social networks apps use, and its impact on team performance.

In fact, previous research that conducted, have frequently used general technical factors to examine the acceptance of the social network apps. This research used social networks technologies related constructs, such as interactivity and collaborative working, to examine their correlation with social networks applications usage and then its association with team performance. Correspondingly, for group performance context, previous research used descriptive measures (Sparrowe et al., 2001; Tajudeen et al., 2018) for instance firms' size and scope, formalization, centralization. In the other hand, some studies Hidayanto and Setyady, (2014) measured group performance rather than focusing on social networks apps, for instance they considered (E-mail, Dropbox, Google Drive, etc.) collaborative tools rather than social network technologies. However, this paper, rather than utilizing descriptive measures, and include other collaborative tools, it examined the impact of social networks apps adoption and its implication on team performance. In addition to the commonly used variables, interactivity and collaborative working were combined with TAM model to make it more suitable and improve it, for use in the research of social network apps and forthcoming new digital solutions that are involved in interactivity and collaboration.

Therefore, this research contributed to the improvement of the measurement of social networks apps use, especially in the context of team performance. The paper also clearly recognizes the influence of social networks technologies 
adoption on over all team performance in terms of information accessibility and exchanging, progress monitoring and effective collaboration and communication.

\section{Conclusion and Future Research}

This study aims to contribute to the research by revealing the factors of social networks applications adoption on organizations, particularly among employees when working as a team or groups and expose its impact on team performance. Perceived usefulness, perceived compatibility, perceived ease of use, and interactivity of social networks technologies predict the acceptance of these applications, to finish group's project. Furthermore, group teamwork that involve cooperative working activities also showed to be enhanced using social networks apps in performing group projects/tasks. This study also exposed that usage of social networks technologies among teams support the accomplishment of group's work positively affects the team performance. Also, the use of social networks applications in doing group's work can advance team performance because it offers better media of communication, and sharing, ideas, information and knowledge, as well as media (documents, different type of files) to enhance the group's contribution. In fact, interaction between group/team members becomes much convenient and easier.

Nevertheless, this research still has some limitations as the research findings only show that social networks applications utilization via smart devices positively influence team's performance, which didn't determine what kind of organizations and the moderation effect of demographic variables for instance (age, gender, education) could help to have more in depth findings. In the future, it is recommended to study more, which can contribute to these findings. For example, by further examining the social network applications and its specifications, to find out what major features will impact employees to adopt these technologies to enhance the team's performance.

\section{References}

Agarwal, R., \& Prasad, J. (1998). The Antecedents and Consequents of User Perceptions in Information Technology Adoption. Decis. Support Syst., 22, 15-29. https://doi.org/10.1016/S0167-9236(97)00006-7

Agarwal, R., \& Prasad, J. (1999). Are Individual Differences Germane to The Acceptance of New Information Technologies?. Decision Sciences, 30(2), 361-391. https://doi.org/10.1111/j.1540-5915.1999.tb01614.x

Akar, E., \& Topçu, B. (2011). An examination of the factors influencing consumers' attitudes toward social media marketing. Journal of Internet Commerce, 10(1), 35-67. https://doi.org/10.1080/15332861.2011.558456

Alavi, M., Wheeler, B. C., \& Valacich, J. S. (1995). Using IT to reengineer business education: an exploratory investigation of collaborative telelearning. MIS Quarterly, 19(3), 293-312. https://doi.org/10.2307/249597

Almuraqab, N. A. S. (2016). M-government adoption factors in the united arab emirates: A partial least-squares approach. International Journal of Business and Information, 11(4), 404-431.

Al-Qirim, N. (2007). The adoption of eCommerce communications and applications technologies in small businesses in New Zealand. Electronic Commerce Research and Applications, 6(4), 462-473. https://doi.org/10.1016/j.elerap.2007.02.012

Bajwa, D. S., \& Lewis, L. F. (2003). Does Size Matter? An Investigation of Collaborative Information Technology Adoption by U.S. Firms. JITTA : Journal of Information Technology Theory and Application, 5(1), 29-46.

Beal, G. M., \& Rogers, E. M. (1960). The Adoption of Two Farm Practices in a Centra! Iowa Community, Ames, Iowa Agricultural and Home Economics Experiment Station, Special Report 26.

Becker, J. D., \& Cline, M. (2005). Effectiveness of collaborative tool usage for virtual team activities. AMCIS 2005 Proceedings, 3.

Bratteteig, T. (1998). The Unbearable Lightness of Grouping Problems of Introducing Computer Support for Cooperative Work. The Proceedings of NOKOBIT, 98.

Creswell, J. W., \& Creswell, J. D. (2017). Research design: Qualitative, quantitative, and mixed methods approaches. Sage publications.

Davis, F. D. (1989). Perceived Usefulness, Perceived Ease of Use, and User Acceptance of Information Technology. MIS Quarterly, 13(3), 319-339. https://doi.org/10.2307/249008

Dennis, A. (1996). Groupware on the Web. Proceedings of the Tools and Methods for Business Engineering Conference (pp. 573-581). Washington DC.

Depietro, R., Wiarda, E., \& Fleischer, M. (1990). The context for change: Organization, technology and environment. 
The Processes of Technological Innovation, 199(0), 151-175.

Devaraj, S., \& Kohli, R. (2003). Performance impacts of information technology: Is actual usage the missing link?. Management Science, 49(3), 273-289. https://doi.org/10.1287/mnsc.49.3.273.12736

El-Gohary, H. (2012). Factors affecting E-Marketing adoption and implementation in tourism firms: An empirical investigation of Egyptian small tourism organisations. Tourism Management, 33(5), 1256-1269. https://doi.org/10.1016/j.tourman.2011.10.013

Elie-Dit-Cosaque, C., \& Pallud, J. (2012). Understanding Collaborative Technologies Adoptive and Post-Adoptive Outcomes: a Longitudinal Study.

Fornell, C., \& Larcker, D. (1981). Evaluating Structural Equation Models with Unobservable Variables and Measurement Error. Journal of Marketing Research, 18(1), 39-50. https://doi.org/10.1177/002224378101800104

Gefen, D., Straub, D., \& Boudreau, M. (2000). Structural Equation Modelling and Regression: Guidelines for Research Practice. Communications of the Association for Information Systems, 4(7), 1-77. https://doi.org/10.17705/1CAIS.00407

Gress, C. L., Fior, M., Hadwin, A. F., \& Winne, P. H. (2010). Measurement and Assessment in Computer Supported Collaborative Learning. Computers in Human Behavior, 26(5), 806-814. https://doi.org/10.1016/j.chb.2007.05.012

Guadagnoli, E., \& Velicer, W. F. (1988). Relation to sample size to the stability of component patterns. Psychological Bulletin, 103(2), 265. https://doi.org/10.1037/0033-2909.103.2.265

Hidayanto, A. N., \& Setyady, S. T. (2014). Impact of Collaborative Tools Utilization on Group Performance in University Students. Turkish Online Journal of Educational Technology-TOJET, 13(2), 88-98.

Hoegl, M., \& Gemuenden, H. G. (2001). Teamwork quality and the success of innovative projects: a theoretical concept and empirical evidence. Organization Science, 12(4), 435-449. https://doi.org/10.1287/orsc.12.4.435.10635

Hong, W., \& Zhu, K. (2006). Migrating to internet-based e-commerce: Factors affecting e-commerce adoption and migration at the firm level. Information and Management, 43(2), $204-221$. https://doi.org/10.1016/j.im.2005.06.003

Jiang, Z., Chan, J., Tan, B. C., \& Chua, W. S. (2010). Effects of interactivity on website involvement and purchase intention. Journal of the Association for Information Systems, 11(1), 1. https://doi.org/10.17705/1jais.00218

Kittle, P., \& Hicks, T. (2009). Transforming the Group Paper with Collaborative Online Writing. Pedagogy, 9(3), 525-538. https://doi.org/10.1215/15314200-2009-012

Koo, C., Wati, Y., \& Jung, J. J. (2011). Examination of how social aspects moderate the relationship between task characteristics and usage of social communication technologies (SCTs) in organizations. International Journal of Information Management, 31(5), 445-459. https://doi.org/10.1016/j.ijinfomgt.2011.01.003

Kreijns, K., \& Kirschner, P. A. (2002). Group awareness widgets for enhancing social interaction in computer supported collaborative learning environments: Design and implementation. In Frontiers in Education, 2002, 32nd Annual (Vol. 1, pp. T3E-T3E). IEEE. https://doi.org/10.1109/FIE.2002.1157973

Kreijns, K., Kirschner, P. A., \& Jochems, W. (2003). Identifying the Pitfalls for Social Interaction in Computer Supported Collaborative Learning Environments: A Review of the Research. Computers in Human Behavior, 19(3), 335-353. https://doi.org/10.1016/S0747-5632(02)00057-2

Lanubile, F., Ebert, C., Prikladnicki, R., \& Vizcaíno, A. (2010). Collaboration Tools for Global Software Engineering. Software, 27(2), 52-55. https://doi.org/10.1109/MS.2010.39

Lee, S., \& Cho, M. (2011). Social media use in a mobile broadband environment: Examination of determinants of Twitter and Facebook use. International Journal of Mobile Marketing, 6(2), 71-87.

Lee, Y., \& Kozar, K. A. (2009). Designing usable online stores: A landscape preference perspective. Information and Management, 46(1), 31-41. https://doi.org/10.1016/j.im.2008.11.002

Line, L. (1997). Virtual Engineering Teams: Strategy and Implementation. Electronic Journal of Information Technology in Construction, 2(1), 1-16.

Lovejoy, K., \& Saxton, G. D. (2012). Information, community, and action: How nonprofit organizations use social 
media. Journal of Computer-Mediated $\quad$ Communication, 17(3), 337-353. https://doi.org/10.1111/j.1083-6101.2012.01576.x

Ma, A. W. W. (2009). Computer Supported Collaborative Learning and Higher Order Thinking Skills: A Case Study of Textile Studies. Interdisciplinary Journal of E-Learning and Learning Objects, 5(1), 145-167. https://doi.org/10.28945/69

Majumdar, A., \& Krishna, S. (2012). Empirical Analysis of Web 2.0 Implications on Collaborative Tool Usage and Team Interactions in Virtual Teams. https://doi.org/10.4108/icst.collaboratecom.2011.247143

Mayfield, A. (2008). What is social media. Retrieved from http://www.au.af.mil/au/awc/awcgate/jfq/mayfield_strat_for_soc_media.pdf

Moore, G., \& Benbasat, I. (1996). Integrating Diffusion of Innovations and Theory of Reasoned Action Models to Predict Utilisation of Information Technology by Endusers (p. 132). Springer. https://doi.org/10.1007/978-0-387-34982-4_10

Munkvold, B. E. (2002). Implementing collaboration technologies in industry: Case examples and lessons learned. Springer Science and Business Media.

Naik, N., \& Kim, D. J. (2010). Virtual Team Success: Towards a Theory of Performance in Virtual Teams. AMCIS (p. 429).

Nikas, A., Poulymenakou, A., \& Kriaris, P. (2007). Investigating antecedents and drivers affecting the adoption of collaboration technologies in the construction industry. Automation in Construction, 16(5), 632-641. https://doi.org/10.1016/j.autcon.2006.10.003

Parveen, F., Jaafar, N. I., \& Ainin, S. (2015). Social media usage and organizational performance: Reflections of Malaysian social media managers. Telematics and Informatics, 32(1), 67-78. https://doi.org/10.1016/j.tele.2014.03.001

Patel, H., Pettitt, M., \& Wilson, J. R. (2012). Factors of Collaborative Working: A Framework for A Collaboration Model. Applied Ergonomics, 43(1), 1-26. https://doi.org/10.1016/j.apergo.2011.04.009

Pituch, K. A., \& Lee, Y. K. (2006). The influence of system characteristics on e-learning use. Computers and Education, 47(2), 222-244. https://doi.org/10.1016/j.compedu.2004.10.007

Ringle, C., Wende, S., \& Will, S. (2005). Smart PLS 2.0 (M3) Beta. Hamburg. Retrieved from http://www.smartpls.de

Rogers, E. M. (1983). Diffusion of Innovations. Free Press, New York.

Rogers, E. M. (1995). Diffusion of Innovations (4th ed.), Free Press, New York.

Serce, F. C., Swigger, K., Alpaslan, F. N., Brazile, R., Dafoulas, G., \& Lopez, V. (2011). Online Collaboration: Collaborative Behavior Patterns and Factors Affecting Globally Distributed Team Performance. Computers in Human Behavior, 27(1), 490-503. https://doi.org/10.1016/j.chb.2010.09.017

Singh, B., \& Avital, M. (2007). The Impact of Collaboration and Competition on Project Performance. Proceedings of the International Conference on Information Systems (ICIS), Montreal, Canada.

Sparrowe, R. T., Liden, R. C., Wayne, S. J., \& Kraimer, M. L. (2001). Social networks and performance of individuals and groups. Acad. Management J., 44, 316-325. https://doi.org/10.2307/3069458

Tajudeen, F. P., Jaafar, N. I., \& Ainin, S. (2018). Understanding the impact of social media usage among organizations. Information and Management, 55(3), 308-321. https://doi.org/10.1016/j.im.2017.08.004

Taylor, S., \& Todd, P. A. (1995). Understanding Information Technology Usage: A Test of Competing Models. Information Systems Research, 6, 144-176. https://doi.org/10.1287/isre.6.2.144

Torkzadeh, G., \& Doll, W. J. (1999). The development of a tool for measuring the perceived impact of information technology on work. Omega, 27(3), 327-339. https://doi.org/10.1016/S0305-0483(98)00049-8

Venkatesh, V., \& Davis, F. D. (2000). A Theoretical Extension of the Technology Acceptance Model: Four Longitudinal Field Studies. Management Science, 46(2), 186-204. https://doi.org/10.1287/mnsc.46.2.186.11926

Wang, Y. M., Wang, Y. S., \& Yang, Y. F. (2010). Understanding the determinants of RFID adoption in the manufacturing industry. Technological Forecasting and Social Change, 77(5), 803-815. https://doi.org/10.1016/j.techfore.2010.03.006 